\title{
Human alveolar capillaries undergo angiogenesis in pulmonary veno-occlusive disease
}

\author{
D.E. Schraufnagel, M. Sekosan, T. McGee, M.B. Thakkar
}

Human alveolar capillaries undergo angiogenesis in pulmonary veno-occlusive disease. D.E. Schraufnagel, M. Sekosan, T. McGee, M.B. Thakkar. CERS Journals Ltd., 1996. ABSTRACT: The bronchial circulation undergoes angiogenesis in several pathological conditions, such as lung neoplasm and bronchiectasis, but whether the pulmonary circulation can do this has been questioned.

A woman treated with mitomycin $\mathrm{C}$ and 5 -fluorouracil developed progressive, fatal pulmonary hypertension over 5 months. In addition to light and transmission electron microscopic examination of her lung, her pulmonary vasculature was cast and the casts were studied with scanning electron microscopy.

Light microscopy showed that she had pulmonary veno-occlusive disease and angiomatoid capillary growth in the alveolar walls. Transmission electron microscopy confirmed the presence of pulmonary hypertension and showed thickened endothelial basement membrane. Scanning electron microscopy of the cast blood vessels showed distortion and destruction of alveolar capillaries prohibiting the passage of erythrocytes. Large new capillaries developed on top of, and were connected to, the shrivelled capillaries that made up the alveolar wall. The new capillaries were larger and fewer, which reduced the alveolar-capillary interface. Arteries and veins were irregularly narrowed and the veins had broad muscularity. Oedema was present, and the pulmonary lymphatics were extensively cast, especially in the lobular septa, but the lymphatics had a normal appearance.

It appears that this patient suffered extensive capillary damage and venous occlusion and that the response was extensive new capillary formation, sometimes in angiomatoid configurations, and hypertrophy of pulmonary veins and arteries. Casting the microvasculature and viewing it with scanning electron microscopy identified new alveolar capillaries in this patient with acquired pulmonary hypertension.

Eur Respir J., 1996, 9, 346-350.
Depts of Medicine and Pathology, University of Illinois at Chicago, Chicago, IL, USA.

Correspondence: D.E. Schraufnagel Section of Respiratory and Critical Care Medicine

Dept of Medicine M/C 787

The University of Illinois at Chicago

840 S. Wood St

Chicago

IL 60612-7323

USA

Keywords: Corrosion casting

mitomycin C

pulmonary hypertension

pulmonary veno-occlusive disease

scanning electron microscopy

Received: July 41995

Accepted after revision November 61995

This study was supported in part by the James E. Liston Fund for the study of Adult Respiratory Distress Syndrome.
Most pathological states associated with new blood vessel growth in the lung, such as neoplasms, bronchiectasis, and lung abscesses, are associated with proliferation of the bronchial rather than the pulmonary circulation [1-3]. In experimental pulmonary hypertension in rats, produced by monocrotaline [4] or bleomycin [5], new blood vessels have been found on the pleural surface [4] and the peribronchial domain [5], but not among the alveolar capillaries. Such studies in experimental animals and observations in common clinical situations have led to the speculation that pulmonary capillaries cannot undergo angiogenesis. It has been suggested that there may be a lack of pericapillary matrix, because the lung parenchyma has scant tissue and cells, being mostly surrounded by alveolar air. This is teleologically appealing because angiogenesis in the alveoli would probably interfere with blood oxygenation. Evidence against this hypothesis comes from the rare clinical condition, pulmonary capillary haemangiomatosis, where capillaries appear to be found in the intralobular fibrous septa and alveolar walls [6-9].

Part of the difficulty of showing angiogenesis may result from the limitations of light and transmission electron microscopy that give a narrow field of view. On the other hand, scanning electron microscopy of microvascular casts shows the three-dimensional structure over a large area and can easily identify neovascular structures. This technique can distinguish arteries from veins in vessels with diameters as small as 15-20 $\mu \mathrm{m}$. It can distinguish different forms of capillaries $[10,11]$ and show the form that new blood vessels take as they develop [12]. Lymphatics are also easily identified by their unique form [13].

A young woman treated for an anal carcinoma developed relentlessly progressive, fatal pulmonary hypertension. The lung was examined for microvascular changes and angiogenesis of alveolar capillaries was found, in addition to other abnormalities. 


\section{Methods}

\section{Case history}

A smoking, but healthy, 42 year old woman developed squamous cell carcinoma of the anus and was treated with 3,000 centigray of external X-irradiation, 5-fluorouracil, $1,420 \mathrm{mg}$ daily for 4 days, and $14 \mathrm{mg}$ of mitomycin C. A month later she had a second cycle of 5-fluorouracil. Two months later she was hospitalized for dehydration as a result of diarrhoea. Her chest film had increased markings and the patient's oxygen saturation was $92 \%$ when she was breathing room air. Three and a half months after receiving the chemotherapy, she gradually developed myalgia, dyspnoea, and dry cough. She was hospitalized and was found to have crackles at the lung bases, leucocytosis and mild anaemia. The arterial $\mathrm{pH}$ was 7.38, arterial carbon dioxide tension $\left(\mathrm{Pa}_{\mathrm{a}} \mathrm{CO}_{2}\right)$ was $3.3 \mathrm{kPa}(25 \mathrm{mmHg})$, and arterial oxygen tension $\left(\mathrm{Pa}, \mathrm{O}_{2}\right)$ was $5.5 \mathrm{kPa}(41 \mathrm{mmHg})$, whilst breathing room air. Chest film showed prominent pulmonary vasculature, cardiomegaly, a small right pleural effusion, and increased interstitial and alveolar markings. The patient was intubated and mechanically-ventilated with $100 \%$ oxygen and given antibiotics and corticosteroids. Bronchoalveolar lavage was negative for pneumocystis, tuberculosis, fungi, legionella and viruses. Pleural effusion was transudative. A transoesophageal echocardiogram showed right ventricular enlargement, decreased right ventricular systolic function, and tricuspid and pulmonic insufficiency.

The patient improved and was discharged on $3 \mathrm{~L}$ of oxygen and $40 \mathrm{mg}$ of prednisone daily. Her forced vital capacity (FVC) was $2.8 \mathrm{~L}$ (100\% predicted), forced expired volume in one second (FEV1) was $1.9 \mathrm{~L}$ (78\% pred), and FEV1/FVC was 0.69 . Total lung capacity (TLC) was $3.5 \mathrm{~L}$ ( $82 \%$ pred), functional residual capacity was $2.2 \mathrm{~L}$ (90\% pred), and gas transfer factor was 2.98 $\mathrm{mL} \cdot \mathrm{min}^{-1} \cdot \mathrm{mmHg}^{-1}(19 \%$ pred $)$. The radiographic lung shadows cleared, but the pulmonary arteries and right ventricle progressively increased in size. Over the next month, she developed cor pulmonale with severe dyspnoea, cough, and right upper quadrant abdominal pain. The patient entered the hospital for the last time in respiratory distress. Her pulse was 100 beats $\cdot \mathrm{min}^{-1}$, respiratory rate was 30 breaths $\cdot \mathrm{min}^{-1}$, temperature was $37.5^{\circ} \mathrm{C}$, and blood pressure was $94 / 60 \mathrm{mmHg}$. She had jugular venous distension, bibasilar crackles and pedal oedema. She had a parasternal heave, an increased pulmonic component of the second heart sound, and a III/VI systolic murmur at the left sternal border. The liver was enlarged, pulsatile and tender. Abnormal blood chemistries included: sodium of $130 \mathrm{mmol} \cdot \mathrm{L}^{-1}$, bicarbonate of $10 \mathrm{mmol} \cdot \mathrm{L}^{-1}$, total bilirubin of $1.9 \mathrm{mg} \cdot \mathrm{dL}^{-1}\left(32 \mu \mathrm{mol} \cdot \mathrm{L}^{-1}\right)$, aspartate aminotransferase (SGOT) of 3,075 $\mathrm{U} \cdot \mathrm{L}^{-1}$, alanine aminotransferase (SGPT) of 2,395 U.L-1, alkaline phosphatase of $157 \mathrm{U} \cdot \mathrm{L}^{-1}$, lactate dehydrogenase of $3,938 \mathrm{U} \cdot \mathrm{L}^{-1}$, and lactic acid of $6.4 \mathrm{mEq} \cdot \mathrm{L}^{-1}$. Urinalysis was normal, with the exception of 10 erythrocytes and 2 leucocytes per high power field (hpf). Abnormalities of the blood cell profile included: a leucocyte count of $\left(15.2 \times 10^{9} \cdot \mathrm{L}^{-1}\right)$ $\left(15,200\right.$ cells $\left.\cdot \mu L^{-1}\right)$ with $89 \%$ neutrophils and $1 \%$ bands (nonsegmented (immature) polymorpho-nuclear leucocyte), and haemoglobin of $10.8 \mathrm{~g} \cdot \mathrm{dL}^{-1}\left(108 \mathrm{~g} \cdot \mathrm{L}^{-1}\right)$. There was mild anisocytosis with a few schistocytes on the peripheral smear. The prothrombin time was $17 \mathrm{~s}$ but partial thromboplastin time was normal.

Before being placed on a ventilator, the patient's $\mathrm{pH}$ was $7.26, \mathrm{~Pa}_{\mathrm{a}} \mathrm{CO}_{2}$ was $2.8 \mathrm{kPa}(21 \mathrm{mmHg})$, and $P \mathrm{a}, \mathrm{O}_{2}$ was $9.6 \mathrm{kPa}(72 \mathrm{mmHg})$ on a $50 \%$ Venturi mask. Right atrial pressure was $24 \mathrm{mmHg}$, right ventricular pressure 99/11 $\mathrm{mmHg}$, and pulmonary artery pressure $92 / 51 \mathrm{mmHg}$, and pulmonary capillary wedge pressure $22 \mathrm{mmHg}$. Cardiac output was $3.12 \mathrm{~L} \cdot \mathrm{min}^{-1}$. A lung scan and pulmonary angiogram were negative. The patient was given heparin, antibiotics and a high dose of corticosteroids. The last chest radiographs showed pulmonary oedema and pleural effusions. After 2 weeks, at the patient's request, she was extubated and died 3 days later.

\section{Histological methods}

The autopsy was limited to the thorax and performed $5 \mathrm{~h}$ after death. The left lung was fixed by perfusion with $4 \%$ formaldehyde through the bronchus. Small pieces were removed and fixed in buffered $2 \%$ glutaraldehyde for transmission electron microscopy.

The right lung was removed and the vasculature was rinsed with heparinized saline until the effluent was clear. One hundred and twenty millilitres of partially polymerized methyl methacrylate (Mercox, Ladd Research Industries, Burlington, VT, USA) was mixed with the accelerator and injected into the pulmonary artery to fill the lung vasculature. The plastic was allowed to harden for $1 \mathrm{~h}$. Sections were taken for light microscopy and the lung was then placed in sodium hydroxide solution until the tissue was digested. The remaining casts were rinsed and cut into pieces approximately $1 \mathrm{~mm}$ thick. The specimens were fastened to aluminum studs with double-sided tape or silver cement, sputter-coated with palladium-gold, and viewed with a JEOL, (Tokyo) JSM35C, scanning electron microscope. Tissue for light microscopy was dehydrated, and embedded in paraffin in the usual manner. Slides were stained with haematoxylin and eosin and elastic van-Gieson. For transmission electron microscopy, the tissue was submerged in $2.5 \%$ cacodylate-buffered glutaraldehyde and minced into 1 $\mathrm{mm}^{3}$ pieces. After fixation for $4 \mathrm{~h}$, the tissue was rinsed with the buffer. The pieces were postfixed in $1 \%$ osmium tetroxide for $1 \mathrm{~h}$, dehydrated in graded concentrations of alcohol and propylene oxide and embedded in Epon 812. Thin sections were cut and mounted on copper grids, stained with uranyl acetate and lead citrate and examined in a JEOL $100 \mathrm{~S}$ transmission electron microscope.

\section{Results}

At autopsy, the patient had bilateral hydrothoraces, with $400 \mathrm{~mL}$ of fluid on the right side and $250 \mathrm{~mL}$ on the 
left. The heart weighed $350 \mathrm{~g}$ and was dilated. Its right ventricular wall was $5 \mathrm{~mm}$ thick and its left wall was 15 $\mathrm{mm}$ thick. The valve circumferences were normal. The right lung weighed $460 \mathrm{~g}$ and the left weighed $450 \mathrm{~g}$. Anthracotic pigmentation was present on the pleura. The cut surface of the left lung showed moderate emphysema.

Light microscopy confirmed that moderate irregular emphysema existed, especially in the upper lobes. Scattered interstitial anthracotic pigment was more accentuated around bronchioles. There was mild patchy fibrosis and many haemosiderin-laden alveolar macrophages. Both were more pronounced near the interlobular septa. Medium-sized arteries had medial thickening and intimal proliferation. Small arteries and veins had eccentric fibrous plaques in their walls as well as occasional bridging of their lumens by fibrous bands. The intralobular septa were fibrosed and had dilated lymphatics. The media and intima of the pulmonary veins were thickened and their lumens were narrowed and often completely obstructed (fig. 1). They often had distinct internal and external elastic laminae. Dilated lymphatics often surrounded occluded veins. Angiomatoid structures, which were more apparent after viewing the casts, joined alveolar capillaries (fig. 2). These clusters of dilated capilla-

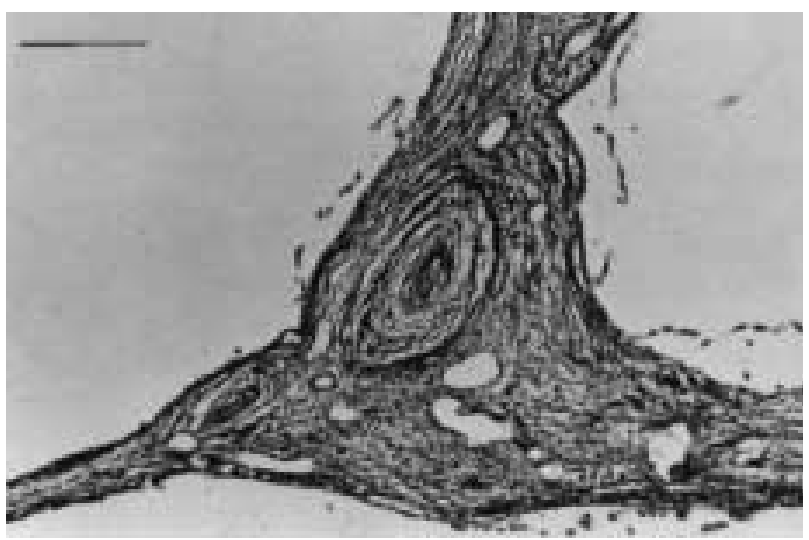

Fig. 1. - The light micrograph shows small pulmonary veins completely occluded. The veins lie in the septum, which has dilated lymphatics. (Elastic-van Gieson stain; Internal scale bar $=40 \mu \mathrm{m}$, original magnification $\times 125)$.

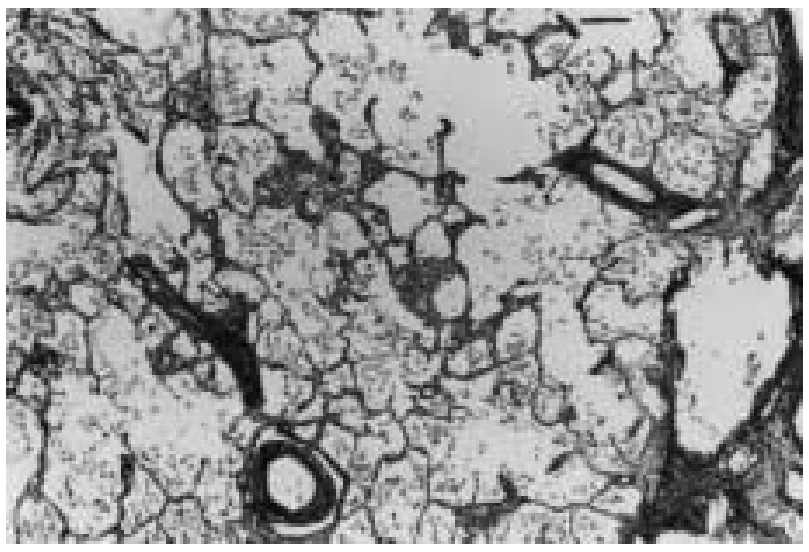

Fig. 2. - Low power view showing alveoli that have patches of extensive new alveolar capillaries on their walls. (Elastic-van Gieson stain; Internal scale bar $=558 \mu \mathrm{m}$, original magnification $\times 16$ ). ries more often occurred away from the interlobular septa. Transmission electron microscopy confirmed light microscopic findings showing increased muscularity of the small arteries and veins and endothelial damage.

Scanning electron microscopy of the vascular casts showed that the most abnormal site was the capillary. The capillaries were so distorted and destroyed that it was difficult to imagine erythrocytes passing through them. Large capillaries developed on top of, and were connected to, the small distorted capillaries that made up the alveolar walls (fig. 3). The small capillaries that occupied the normal position in the alveolar wall were pinched off and the large capillaries grew around them (fig. 4). The normal space between capillaries was virtually eliminated in many areas of the lung. Normally, capillaries are strikingly uniform in diameter, seldom smaller than $5 \mu \mathrm{m}$ or larger than $8 \mu \mathrm{m}$. In the lung of this patient, capillaries $16-18 \mu \mathrm{m}$ in diameter were commonly connected to and interspersed with capillaries that were only 1-2 $\mu \mathrm{m}$ in width (fig. 5). The larger capillaries had the general pattern and structure of normal alveolar capillaries but had less branching and density, and lacked the delicate basket-like structure that cradles alveoli. Remains of adherent inflammatory cells were found in cast segments before contortions. Arteries were constricted. The surfaces of the venous casts were tex-

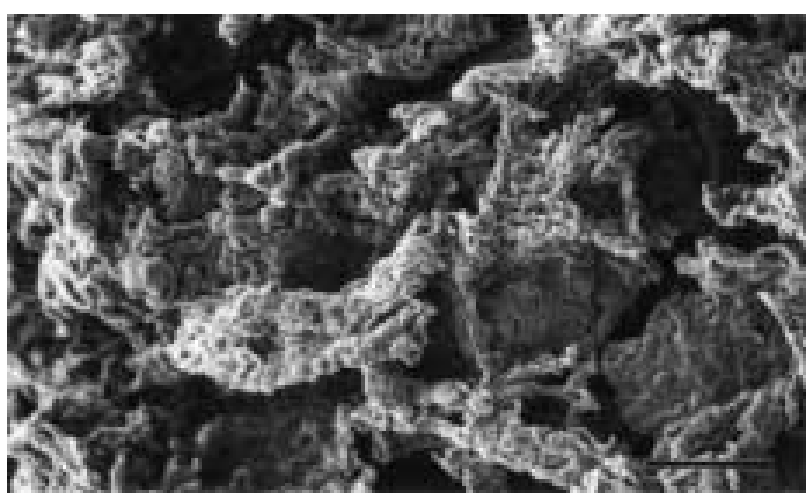

Fig. 3. - Casts of the pulmonary microcirculation showing great distortion of the alveolar capillaries. Outlines of alveoli (above open arrowheads) are evident but the alveolar septa are thickened with extra capillary growth. (Internal scale bar $=100 \mu \mathrm{m}$ ).

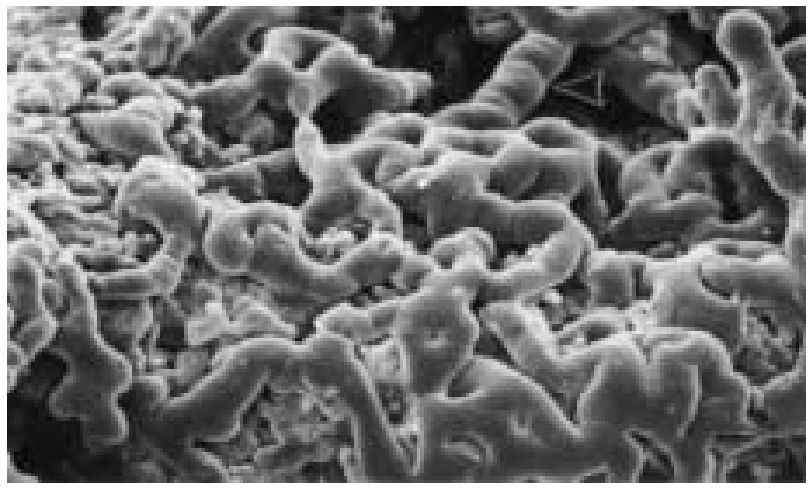

Fig. 4. - Scanning electron micrograph showing extensive large capillaries not only overgrowing the small base capillaries but spanning alveoli (triangular arrowhead). the new capillaries have only a fraction of the alveolar-capillary interspace of normal capillaries (Internal scale bar $=10 \mu \mathrm{m})$. 


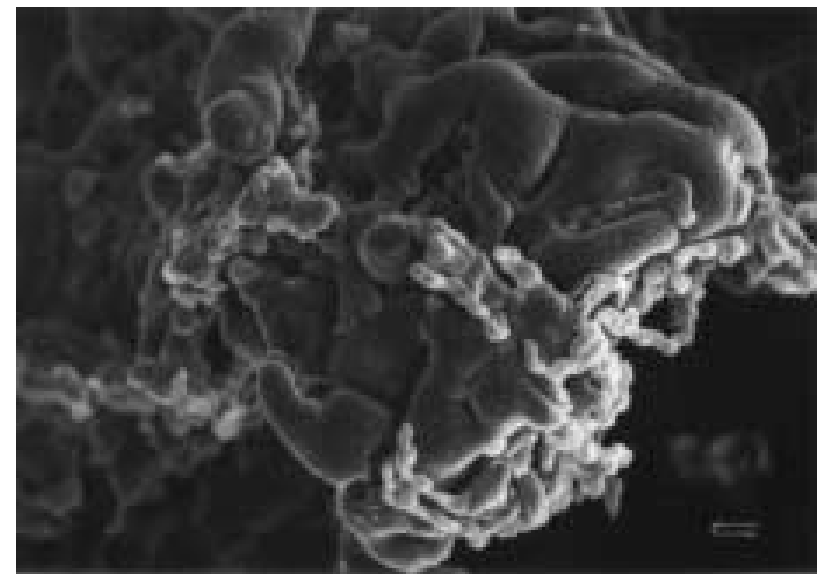

Fig. 5. - Micrograph showing the new large capillaries (small arrow) are connected to the underlying alveolar capillaries. (Internal scale bar $=10 \mu \mathrm{m})$.

tured and their cell junctions were marked by furrows that corresponded to intercellular ridges, features not found on normal veins. The venous casts did not have thin ring-like bands commonly seen in experimental animals [14], but broader less regular narrowings that more closely resembled those of the muscular walls of arteries and corresponded with the muscularization of pulmonary veins on light microscopy. Cast lymphatics were also frequently found but had a normal appearance, which is characteristic and not difficult to distinguish from blood capillaries $[13,15]$.

\section{Discussion}

This study refutes the assertion that new blood vessel growth in the lung only results from expansion of the bronchial circulation. It appears to show that damaged alveolar capillaries can be replaced. This angiogenesis appears to be a compensation but the new capillaries were larger, scantier and less orderly than the normal vascular bed, probably resulting in this patient's inability to adequately oxygenate her blood. Also, the space occupied by the smaller, effete capillaries might cause a larger diffusion distance. Our study does not identify the mechanism of the capillary damage. Although it does not rule out that the veins are the main site of injury, the electron microscopic observations suggest that the most damaged component was the alveolar capillary.

The findings were only possible with scanning electron microscopy of cast microvasculature. Viewing the microvasculature of other patients with this disorder may indicate how frequently such pathological changes occur. Alveolar angiogenesis is not easily detected with sectioning histological techniques. Although microangiopathic haemolysis has been reported in idiopathic pulmonary hypertension [16], the nature of capillary changes is difficult to visualize without scanning electron microscopy of casts. In our case, the angiomatoid structures were not detected before finding them in the capillary casts. The transmission electron microscopy was similar to past studies on pulmonary veno-occlusive disease
[17]. "Pseudoangiomatous features", capillary clumps, have been reported in the adventitia of pulmonary veins [18], but have been considered collateral circulation arising from the bronchial circulation in the walls of the occluded pulmonary veins $[19,20]$.

Pulmonary capillary haemangiomatosis was first reported by WaGENVOORT et al. [6] in 1978. Less than 20 cases have been reported since [9]. In this condition, new capillary-sized, thin-walled blood vessels grow in the lung interstitium and in and around pulmonary blood vessels and airways. Pulmonary capillary haemangiomatosis is associated with pulmonary hypertension and pulmonary veno-occlusive disease [21], and has been described after radiation therapy and anti-oestrogen therapy in a patient with breast cancer [22]. On light microscopic sections (fig. 2 ), our patient had angiomatoid areas consistent with pulmonary capillary haemangiomatosis, but scanning electron microscopy of the vascular casts showed that the predominant lesion was diffuse capillary destruction and regrowth of virtually all the alveolar capillaries fields. Other forms of pulmonary hypertension could also have capillary destruction as their main pathogenic mechanism. Such a finding would be important not only in understanding the disease but also in evaluating treatment. The distorted capillaries in this patient would make her an unlikely candidate to respond to vasoactive agents.

Pulmonary toxicity from mitomycin $\mathrm{C}$, the alkylating agent, is well-documented and pulmonary veno-occlusive disease has been reported in patients taking mitomycin C, bleomycin, and cis-platinum [23] and other chemotherapeutic agents [24]. Pulmonary angiomatoid changes have also been reported in association with a haemolytic-uraemic syndrome [25], noncardiogenic pulmonary oedema [26], and pulmonary hypertension [27]. Patients with mitomycin-induced microangiopathic haemolytic anaemia had dyspnoea, hypoxaemia, thrombocytopenia, thrombi in the pulmonary microvasculature, dilated pulmonary capillaries, and renal failure [25-27]. Our patient had obstruction of the pulmonary microcirculation without haemolytic anaemia, thrombocytopenia, or renal failure. Although occasional schistocytes were seen on the peripheral blood smear, the patient did not have significant haemolysis and never required a blood transfusion.

Mitomycin may generate superoxide radicals in the presence of oxygen, and exposure to high concentrations of oxygen may potentiate lung injury as it does in those treated with bleomycin. Our patient underwent two rectal examinations under anaesthesia 1 month after receiving mitomycin: the first used general (intravenous) anaesthesia with an unspecified inspired oxygen concentration and the second used caudal anaesthesia with $4 \mathrm{~L}$ oxygen via nasal cannula. No pulmonary symptoms occurred during that admission, but a contribution of oxygen to the lung injury cannot be excluded. Radiation therapy to the lung can cause pulmonary veno-occlusive disease [28]. The endothelium is most sensitive to the damaging effects of irradiation, but this patient's lungs were not in the radiographic field.

Clinically, our patient was recognized at an early stage to have a pulmonary hypertension caused by capillary 
damage because of the progressive dyspnoea, hypoxia, and increased pulmonary artery size visualized radiographically with an otherwise nearly normal chest film, pulmonary function tests, and nucleotide lung scans. Heparin and corticosteroids were not beneficial.

Acknowledgement: The authors thank the Electron Microscopy Facility of the Research Resources Center, University of Illinois at Chicago for help and equipment to conduct this study.

\section{References}

1. Cudkowicz L. Bronchial arterial circulation in man. In: Moser KM, ed. Pulmonary Vascular Disease. New York, Marcel Dekker, 1979; p. 111-232.

2. Charan NB, Carvalho PG. The bronchial circulation in chronic lung infections. In: Butler J, ed. The Bronchial Circulation. New York, Marcel Dekker, 1992; pp. 535549.

3. Hyde RW. Circulation of lung neoplasms. In: Butler J, ed. The Bronchial Circulation. New York, Marcel Dekker, 1992; pp. 551-578.

4. Schraufnagel DE. Monocrotaline-induced angiogenesis: differences between bronchial and pulmonary vasculature. Am J Pathol 1990; 137: 1083-1090.

5. Peao MN, Aguas AP, de Sa CM, Grande NR. Neoformation of blood vessels in association with rat lung fibrosis induced by bleomycin. Anat Rec 1994; 238: 57-67.

6. Wagenvoort CA, Beestra A, Spijker J. Capillary hemangiomatosis of the lungs. Histopathology 1978; 2: 401406.

7. Heath D, Reid R. Invasive pulmonary haemangiomatosis. Br J Dis Chest 1985; 79: 284-294.

8. Langleben D, Heneghan JM, Batten AP, et al. Familial pulmonary capillary hemangiomatosis resulting in primary pulmonary hypertension. Ann Intern Med 1988; 109: 106-109.

9. Tron V, Magee F, Wright JL, Colby T, Churg A. Pulmonary capillary hemangiomatosis. Hum Pathol 1986; 17: 1144-1150.

10. Schraufnagel DE. Corrosion casting of the lung for scanning electron microscopy. In: Schraufnagel DE, ed. Electron Microscopy of the Lung. New York, Marcel Dekker, 1990; pp. 257-297.

11. Aharinejad S, Lametschwandtner A. In: Microvascular Corrosion Casting in Scanning Electron Microscopy: Techniques and Applications. Vienna-New York, Springer, 1992.

12. Caduff JH, Fischer LC, Burri PH. Scanning electron microscope study of the developing microvasculature in the postnatal rat lung. Anat Rec 1986; 216: 154-164.

13. Schraufnagel DE, Llopart Basterra J, Hainis K, Sznajder JI. Lung lymphatics increase after hyperoxic lung injury: an ultrastructural study of casts. Am J Pathol 1994; 144: 1393-1402.

14. Schraufnagel DE, Patel KR. Sphincters in pulmonary veins: an anatomic study in rats. Am Rev Respir Dis 1990; 141: 721-726.

15. Schraufnagel DE. Forms of lung lymphatics: a scanning electron microscopic study of casts. Anat Rec 1992; 233: 547-554.

16. Jubelirer SJ. Primary pulmonary hypertension: its association with microangiopathic hemolytic anemia and thrombocytopenia. Arch Intern Med 1991; 151: 1221 1223.

17. Kay JM, de Sa DJ, Mancer JF. Ultrastructure of lung in pulmonary veno-occlusive disease. Hum Pathol 1983; 14: 451-456.

18. Daroca PJ Jr, Mansfield RE, Ichinose H. Pulmonary veno-occlusive disease: report of a case with pseudoangiomatous features. Am J Surg Pathol 1977; 1: 349-355.

19. Stovin PGI, Mitchinson MD. Pulmonary hypertension due to obstruction of the intrapulmonary veins. Thorax 1965; 20: 106-113.

20. Carrington CB, Liebow AA. Pulmonary veno-occlusive disease. Hum Pathol 1970; 1: 322-324.

21. Eltorky MA, Headley AS, Winer-Muram H, Garrett HE Jr, Griffin JP. Pulmonary capillary hemangiomatosis: a clinicopathologic review. Ann Thorac Surg 1994; 57: 772-776.

22. Domingo C, Encabo B, Roig J, Lopez D, Morera J. Pulmonary capillary hemangiomatosis: report of a case and review of the literature. Respiration 1992; 59: 178180.

23. Joselson R, Warnock M. Pulmonary veno-occlusive disease after chemotherapy. Hum Pathol 1983; 14: 88-91.

24. Lombard CM, Churg A, Winokur S. Pulmonary venoocclusive disease following therapy for malignant neoplasms. Chest 1987; 92: 871-876.

25. Chang-Poon VYH, Hwang WS, Wong A, Berry J, Klassen J, Poon M. Pulmonary angiomatoid vascular changes in mitomycin $\mathrm{C}$-associated hemolytic-uremic syndrome. Arch Pathol Lab Med 1985; 109: 877-878.

26. Jolivet J, Giroux L, Laurin S, Gruber J, Bettez P, Band PR. Microangiopathic hemolytic anemia, renal failure, and noncardiogenic pulmonary edema: a chemotherapyinduced syndrome. Cancer Treat Rep 1983; 67: 429434.

27. McCarthy JT, Staats BA. Pulmonary hypertension, hemolytic anemia, and renal failure: a mitomycin-associated syndrome. Chest 1986; 89: 608-611.

28. Kramer MR, Estenne M, Berkman N, et al. Radiationinduced pulmonary veno-occlusive disease. Chest 1993; 104: 1282-1284. 